\title{
Cognitive Impairment At 3, 6 and 12 Month After the First-Ever Stroke Among Lebanese Survivors: Incidence and Risk Factors
}

Celina Boutros ( $\nabla$ celinaboutros@gmail.com )

Institut Mondor de Recherche Biomédicale (IMRB)-Inserm U955, Ecole Doctorale Science de la Vie et de la Santé, Université Paris-Est, Créteil, Paris, France

\section{Walaa Khazaal}

Neuroscience Research Center, Faculty of Medical Sciences, Lebanese University, Hadath, Lebanon.

\section{Maram Taliani}

Neuroscience Research Center, Faculty of Medical Sciences, Lebanese University, Hadath, Lebanon.

\section{Pascale Salameh}

Institut National de Santé Publique, Epidémiologie Clinique et Toxicologie (INSPECT-LB), Beirut, Lebanon.

Hassan Hosseini

Henri Mondor Hospital AP-HP, Créteil, France

\section{Najwane Said Sadier}

Neuroscience Research Center, Faculty of Medical Sciences, Lebanese University, Hadath, Lebanon.

\section{Research Article}

Keywords: Post-stroke cognitive impairment, incidence, stroke survivors, predictors, stroke disabilities, Lebanon.

Posted Date: January 19th, 2021

DOl: https://doi.org/10.21203/rs.3.rs-147073/v1

License: (c) (i) This work is licensed under a Creative Commons Attribution 4.0 International License. Read Full License 


\title{
Cognitive impairment at 3, 6 and 12 month after the first-ever stroke among Lebanese survivors: Incidence and Risk factors
}

Celina Boutros*1, Walaa Khazaal ${ }^{2 \mathrm{C} o}$, Maram Taliani ${ }^{2 \mathrm{Co}}$, Pascale Salameh ${ }^{3,4}$, Najwane Said Sadier ${ }^{2}$, Hassan

$$
\text { Hosseini }{ }^{1,4,5} \text {. }
$$

1. Institut Mondor de Recherche Biomédicale (IMRB)-Inserm U955, Ecole Doctorale Science de la Vie et de la Santé, Université Paris-Est, Créteil, Paris, France.

2. Neuroscience Research Center, Faculty of Medical Sciences, Lebanese University, Hadath, Lebanon.

3. Lebanese University, Faculty of Pharmacy, Hadath, Lebanon.

4. Institut National de Santé Publique, Epidémiologie Clinique et Toxicologie (INSPECT-LB), Beirut, Lebanon.

5. Henri Mondor Hospital AP-HP, Créteil, France.

*Corresponding author : Celina Boutros, Institut Mondor de Recherche Biomédicale (IMRB)-Inserm U955, Ecole Doctorale Science de la Vie et de la Santé, Université Paris-Est, Créteil, Paris, France. Email: celinaboutros@gmail.com-celina.boutros@u-pec.fr. ORCID ID:0000-0001-7789-8478.

${ }^{\mathrm{Co}}$ Co-authors: Contributed equally to this work: Walaa Khazaal, Maram Taliani.

\begin{abstract}
Cognitive impairment is a prevalent outcome of stroke, affecting the quality of life and increasing the disability. Its risk factors are unknown in Lebanon. Therefore, the aims of this study were to evaluate the cognitive impairment incidence among Lebanese stroke survivors at 3, 6 and 12 month post stroke, and to identify the associated factors. A multicenter longitudinal prospective study was conducted in 10 hospitals of Beirut and Mount Lebanon among 150 subjects aged $\geq 18$ years old between February 2018 until May 2019. The MiniMental State Examination assessed the cognitive function. Univariate and Multivariable analyses were performed to identify the predictors of the post stroke cognitive impairment. A p-value $<0.05$ was considered statistically significant. At 3 month post stroke, $74.8 \%$ were cognitively impaired versus $46.7 \%$ and $37.6 \%$ at 6 and 12 month post stroke respectively. Older age, past smoking, presence of a caregiver, sedentary $\geq 12$ hours, aphasia at the time of stroke occurrence, the length of hospital stay, severe stroke, high disability degree, post stroke anxiety and depression, epileptic seizures and physical disorders were the risk factors inducing cognitive decline. Whereas, the high education level, the employment and the history of diabetes mellitus played a protective role for the cognitive function. Findings reveal levels of cognitive impairment post-stroke that are concerning. Thus, primary and secondary prevention is essential to reduce its incidence and to cope with its burden.
\end{abstract}

Keywords: Post-stroke cognitive impairment, incidence, stroke survivors, predictors, stroke disabilities, Lebanon. 


\section{Introduction}

Stroke is a pervasive health concern touching approximately 17 million people worldwide each year[1]. The shortterm, medium-term and long-term consequences of stroke are dramatic, with a high mortality rate, requiring particularly heavy daily care[2].

Post-stroke cognitive impairment (PSCI) is very common. This places an enormous burden on caregivers and the healthcare system[3]. Stroke patients have a high potential to develop mild to severe cognitive decline within the first year of stroke onset[4]. Mild cognitive impairment involves deficits in memory areas whereas cognitive areas remain unharmed and stroke survivors are able to execute their activities of daily living (ADL). In contrary, patients with severe cognitive impairment (dementia) develop a loss or deterioration of the physical function and many cognitive domains $[5,6]$.

Two studies, in China and Norway, revealed that $66.6 \%$ of stroke patients at the early stage and $69.8 \%$ to $96 \%$ patients in the following 3-6 month after onset had cognitive impairment[7, 8]. It alters attention and concentration, executive function, memory, language, and visuospatial cognitive domains[9, 10]. A systematic review conducted by Lo et al. in 2019 including thirteen studies showed highest proportion of global cognitive impairment in African Americans (48\%) followed by whites (47\%), Koreans (45\%), Nigerians (40\%), and Singaporean Chinese (35\%)[11].

Moreover, international data classified the demographic, lifestyle, clinical, and stroke-related factors as important contributors and risk factors of PSCI[11-14].

Based on the classification of the World Bank country (2008-2012) and the World Health Organization (WHO), Lebanon is an Arab country in the Middle East region ranked among low and middle-income countries where stroke is supposed to be the second cause of death in the country[15].

Many papers were published on the stroke burden, prevalence, risk factors, risk score, care and outcome in Lebanon[15-19] . However, so far, no study in the Middle East and North Africa region, including Lebanon, has been addressed and has focused on the incidence of PSCI and their predictors, where incorporates the importance of the objectives of this study. They aimed to profile the cognitive impairment of stroke survivors at 3,6 and 12 months after stroke and identify the factors associated with the global PSCI in Lebanese territory.

\section{Methods}

To secure an adequate reporting of this work, we followed The Strengthening the Reporting of Observational studies in Epidemiology (STROBE) guidelines[20].

\section{Study design}

An epidemiological observational multicenter prospective longitudinal study was conducted at 10 hospitals of Beirut and Mount Lebanon (5 university and 5 non-university hospitals) (Hôtel Dieu de France, Clinique du Levant, Al Hayat Hospital, Mount Lebanon Hospital, Al Sahel Hospital, Rafic Hariri University Hospital, Zahraa Hospital, Hôpital Sacré- Coeur, Kesserwan Medical Center and Middle East Institute of Health). It lasted for 15 month of follow-up, from February 2018 until May 2019. The ethical committees of all the participating hospitals approved the study in line with the World Medical Association Declaration of Helsinki in 2013[21]. 


\section{Participants}

Any Lebanese subject aged $\geq 18$ years old admitted to the hospitals between February 2018 and May 2018, survivor of first-ever ischemic or hemorrhagic stroke well identified by the following codes of the International Classification of Diseases-10 (ICD-10) (I63-I61) was included[22]: cerebrovascular accident, stroke, ischemic stroke, hemorrhagic stroke, intracerebral hemorrhage or embolic/cerebral vascular thrombosis; with a diagnosis confirmed by brain imaging. The exclusion criteria were: being non Lebanese, age $<18$ years old, admission for a recurrent stroke or for Transient Ischemic Accident or having as a medical history the neurological and cognitive disorders. Participants (or their legal representatives) provided a written informed consent to be enrolled in the study.

\section{Sample size}

Considering a prevalence of stroke in Lebanon of 3.9\% depending on the study of Jurjus and collaborators[23], the minimum sample size was calculated using the Epi-info 7 program and estimated at 116 subjects. A sample size of 150 subjects was considered in the study to take into account missing data and the loss to follow-up.

\section{Study procedures}

The investigators were trained to the data collection process. The first visit to the hospitals was crucial to get their approval and to approach the eligible subjects. We interviewed them directly during their admission for their written consent but on the other hand, some of the subjects were contacted by phone due to the approval's delay of some hospitals.

The three other visits to subjects' residences were the essential time sequences devoted for the follow-up and data collection at 3, 6 and 12 month post stroke.

\section{Questionnaire and scales}

A questionnaire was translated from English to Arabic language (maternal language) by a certified and registered translator. It was derived in 5 major sections: the demographic and socio-economic characteristics (age, gender, place of residence, marital status, number of kids, the age of subject's custodian, level of education of the subject and his custodian, employment status, number of household members, number of rooms and type of health insurance), the lifestyle (eating habits, practice of physical activity, alcohol and other substances consumption and the social support), the health indicators (anthropometric indices, family/medical/surgical history, comorbidities, treatment taken by subjects), the disease and its severity (types/ location/ symptoms, length of hospital stay, severity of disease, degree of disability, evaluation of quality of life) and ending by the stroke consequences (neuropsychiatric disorders, cognitive disorders, hyperglycemia, fatigue, post stroke pain, falls, pressure ulcers, pulmonary and urinary infections, deep vein thrombosis, pulmonary embolism, seizures, and recurrence of stroke).

All the questions related to the disease and its consequences were inspired and assessed by standardized measuring instruments and scales validated by previously published international studies. A pre-testing exercise was utilized to measure the appropriateness of the instruments and the constraining factors were rectified. Regarding the accuracy, the study used Cronbach's coefficient alpha to measure the consistency. To generate the Cronbach's alpha results, we conducted a pilot study to validate the instrument then a total Cronbach's alpha of $(r)=0.811$ was obtained. 
The following operational definitions and scales were used:

Stroke ("Jalta Dimaghia" is the arabic synonym, the most familiar and most specific term for the disease in Lebanon): according to the WHO, "it is a clinical syndrome consisting of rapidly developing clinical signs of focal (or global in case of coma) disturbance of cerebral function lasting more than 24 hours or leading to death with no apparent cause other than a vascular origin"'[24].

"Mini-Mental State Examination" (MMSE) is widely used to investigate the cognition recovery. It measures the memory registration, memory recall, attention/calculation, language, and comprehension/judgment. The total score achievable is 30 points, where a higher score indicates superior cognitive function"[25]. The cut-off point is set at 24 defining a normal cognitive function[26] (Cronbach's alpha of $(r)=0.882)$.

"National Institutes of Health Stroke Scale (NIHSS) is one of the most reliable and valid clinical stroke severity measurement instruments[27]. "It's a scale of 15 elements; it reveals the evaluation of consciousness, language, motor function, sensory loss, visual fields, extra-ocular movements, coordination, neglect and speech. It is marked from 0 (without alteration) to a maximum of 42. Scores of 21 or more are usually described as severe”[28]. It's divided into 5 levels :0 :No stroke, 1-4 :minor stroke, 5-15 :moderate stroke, 15-20:moderate to severe stroke, 2142 : severe stroke[29] (Cronbach's alpha of $(r)=0.942)$.

Modified Rankin Scale (mRS) is a scale used to appraise the disability degree in stroke survivors, the most recognized in clinical trials, due to its validity and its ability to distinguish between clinically relevant disability levels and recovery[30]. It's divided into 7 levels from 0 (No symptoms) to 6 (Death)[31]. The mild disability (independence) is graded 0 to 2 and the moderate to severe disability is graded $\geq 3$ [32] (Cronbach's alpha of (r) = 0.946).

Other measures were presented in the Appendix (Additional File 3): the Questionnaire for Verifying Stroke-Free Status (QVSFS)[33], the Quality of life (Short Form Health Survey, SF12)[34], the Hospital Anxiety and Depression Scale (HADS)[35, 36], the Fatigue Severity Scale (FSS)[37, 38].

\section{Data processing and analysis}

Collected data were coded, introduced and entered to the software Statistical Package for Social Sciences (SPSS) version 25 (SPSS ${ }^{\text {TM }}$ Inc., Chicago, IL USA). At first, descriptive analyses were performed using numbers and percentages for qualitative variables and means with standard deviation (SD) for continuous variables. And one way repeated measures Analysis of Variances (ANOVA) was important to assess the cognitive function over time. Second, the univariate analyses were conducted. The Student's t test was used for comparison of means of the quantitative variables with a normal distribution and equal variances, whereas the non-parametric test for quantitative variables with an abnormal distribution and the unequal variances were used. The Chi-square test was used for the comparison of percentages between two qualitative variables. Then, backward stepwise multivariable models were made using logistic regressions to identify variables independently associated with cognitive sequelae. The strength of association was interpreted using the adjusted odds ratio (AOR) with $95 \%$ confidence Interval (CI). A $p$-value <0.05 was considered statistically significant.

\section{Ethical considerations}

Ethical clearance was obtained from the participating hospitals through a formal letter granted from their Ethical Committees. After we informed the subjects about the purpose of the study, a written consent was obtained from those included in the study. Participants were also informed that no damage/risk or good profit for them that may 
result from their collaboration to this study, the participation was on a voluntary basis and they had the right to withdraw at any time. In order to keep confidentiality, all data were kept anonymously in the interview questionnaire and were kept locked and then destroyed once the legal retention period expired.

\section{Results}

A total of 20 hospitals were visited, of which 10 agreed to participate in the study. Out of 183 subjects meeting the required inclusion criteria, 150 were recruited in the study ( $82 \%$ of the response rate), of whom 117 subjects completed all the follow-up (Figure 1. Flow Diagram).

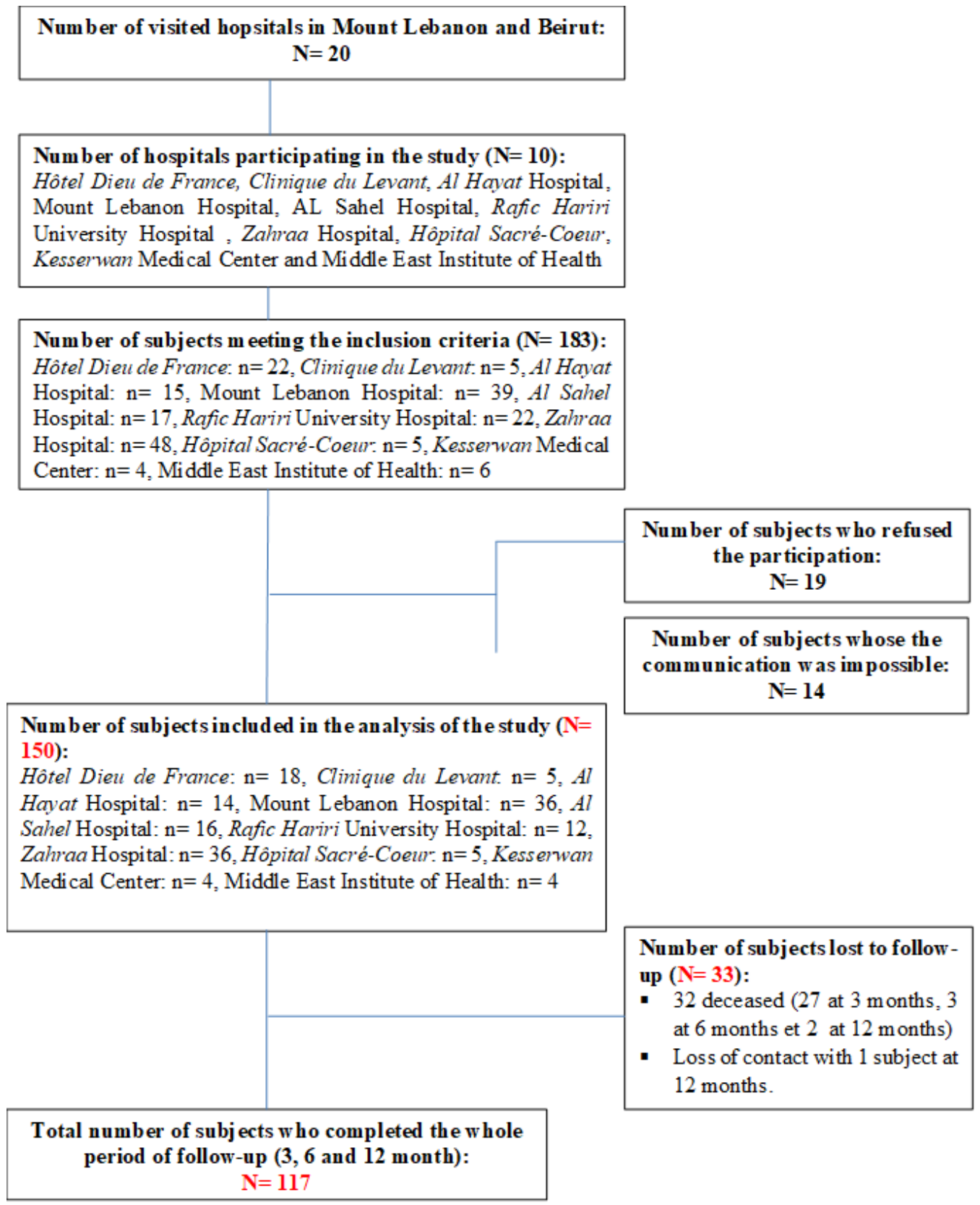

Figure1. Flow diagram of the steps followed to obtain the sample of the study. 


\section{Socio-demographic characteristics of the study participants}

According to Table 1, in total, 58.7\% of the subjects recruited were male. Their mean age was 73.7 with SD of 12 years. The majority (78\%) were married, lived with family members (96.1\%) and 87\% in less crowded houses. An important proportion of the participants were illiterate $(38 \%)$. In addition, $67.3 \%$ without profession or retired versus $20 \%$ stopped their work after stroke.

Table 1. Socio-demographic characteristics of the study population.

\begin{tabular}{|c|c|c|c|}
\hline Variables & Frequency $(N)$ & Percentage (\%) & $\operatorname{Mean}( \pm S D)$ \\
\hline \multicolumn{4}{|l|}{ Gender $(\mathrm{N}=150)$} \\
\hline Male & 88 & 58.7 & \\
\hline Female & 62 & 41.3 & \\
\hline \multicolumn{4}{|l|}{$\operatorname{Age}(\mathrm{N}=150)$} \\
\hline $30-39$ years & 1 & 0.7 & \\
\hline $40-49$ years & 7 & 4.7 & \\
\hline $50-59$ years & 15 & 10.0 & \\
\hline $60-69$ years & 29 & 19.3 & $73.73( \pm 12.08)$ \\
\hline $70-79$ years & 45 & 30.0 & \\
\hline $80-89$ years & 46 & 30.7 & \\
\hline 90 - 99 years & 7 & 4.7 & \\
\hline \multicolumn{4}{|l|}{ Marital Status (N=150) } \\
\hline Single & 14 & 9.3 & \\
\hline Married & 117 & 78.0 & \\
\hline Divorced & 2 & 1.3 & \\
\hline Widowed & 17 & 11.3 & \\
\hline \multicolumn{4}{|l|}{ Family members $(\mathrm{N}=128)$} \\
\hline Alone & 5 & 3.9 & \\
\hline With family members & 123 & 96.1 & \\
\hline \multicolumn{4}{|l|}{ Residence $(\mathrm{N}=150)$} \\
\hline Beirut & 33 & 22.0 & \\
\hline Mount Lebanon & 107 & 71.3 & \\
\hline Bekaa & 3 & 2.0 & \\
\hline North Lebanon & 2 & 1.3 & \\
\hline South Lebanon & 5 & 3.3 & \\
\hline \multicolumn{4}{|l|}{ Education level (N=150) } \\
\hline Illiterate & 57 & 38.0 & \\
\hline Primary/Complementary & 47 & 31.3 & \\
\hline Secondary & 19 & 12.7 & \\
\hline University & 27 & 18.0 & \\
\hline \multicolumn{4}{|l|}{ Employment status post stroke $(\mathrm{N}=150)$} \\
\hline Person without any profession/ retired & 101 & 67.3 & \\
\hline Unemployed & 30 & 20.0 & \\
\hline Employed & 19 & 12.7 & \\
\hline \multicolumn{4}{|l|}{ Social Security $(\mathrm{N}=150)$} \\
\hline No & 25 & 16.7 & \\
\hline Yes & 125 & 83.3 & \\
\hline \multicolumn{4}{|l|}{ Presence of a caregiver $(\mathrm{N}=150)$} \\
\hline No & 98 & 65.3 & \\
\hline Yes & 52 & 34.7 & \\
\hline \multicolumn{4}{|l|}{ Caregiver's age $(\mathrm{N}=52)$} \\
\hline Adult: 20 - 40 years & 9 & 17.3 & \\
\hline Middle age: 40 - 60 years & 35 & 67.3 & \\
\hline Elderly: $>60$ years & 8 & 15.4 & \\
\hline
\end{tabular}




\section{Stroke characteristics and its severity}

A total of $95.3 \%$ of subjects suffered from ischemic stroke compared to $4.7 \%$ suffered from intracerebral hemorrhagic stroke (Figure 2., Additional file 1). Regarding the affected location, 46.7\% of them with the left hemisphere and $40 \%$ with the right hemisphere (Figure 3., Additional file 1).

The majority (70.7\%) were not able to express themselves verbally or in writing at the time of stroke and $70 \%$ experienced a weakness on one side of the body (Figure 4., Additional file 1).

The stroke severity illustrated a percentage at each time of the follow up. At 3 month, $28 \%$ of subjects presented a minor stroke, $40.8 \%$ with a mild stroke, $14.4 \%$ with a moderate stroke and $16.8 \%$ with severe stroke. At 6 and 12 month, most of the subjects had a minor stroke (56.7\% and $60.9 \%$ respectively), and about the quarter $(25.8 \%$ and $20.7 \%$ respectively) were with mild stroke (Figure 5., Additional file 1).

Regarding the degree of disability, the figure 6 (Additional file 1) showed an important percentage (18\%) of subjects who were deceased (mRS=6) 3 month post stroke, whereas, $16 \%$ were bedridden $(\mathrm{mRS}=5)$. These percentages decreased in the 6 to 12 month $(9.8 \%$ and $9.3 \%$ with $\mathrm{mRS}=5,1.6 \%$ and $0.8 \%$ with $\mathrm{mRS}=6$ respectively).

In addition, quality of life scores were summed up in Table 2 (Additional file 1). The means of PCS-12 and MCS12 were approximately between 12 and 16 at 3, 6 and 12 month.

\section{Incidence of PSCI}

Out of 150 enrolled subjects, by 3 month post stroke, 27 were dead (18\%), followed by 3 (2.4\%) in the 6 month and $2(1.7 \%)$ in the 12 month, and 1 subject lost to follow-up at 12 month follow-up. In consequence, we did not have the MMSE of all the subjects.

At 3 month post stroke, the majority of the 123 survivors (74.8\%) were cognitively impaired (MMSE < 24) compared to $25.2 \%$ cognitively intact. The incidence of sequelae gradually decreased over the time at 6 and 12 months post stroke, with percentages of $46.7 \%$ and $37.6 \%$ respectively (Figure 7.).

A one way repeated measures ANOVA was conducted to evaluate the null hypothesis that there was no change in the cognitive function over the time after the first-stroke $(\mathrm{N}=117)$. The results designated a significant time effect, Wilks' Lambda $=0.528, F(2,115)=51.439, p<0.001, \mathrm{n}^{2}=0.472$. Thus, there was evidence to reject the null hypothesis. Follow-up comparisons indicated that each pairwise difference was significant, $p<0.001$. There was a significant increase of MMSE scores over time, suggesting that the cognitive function improves over time.

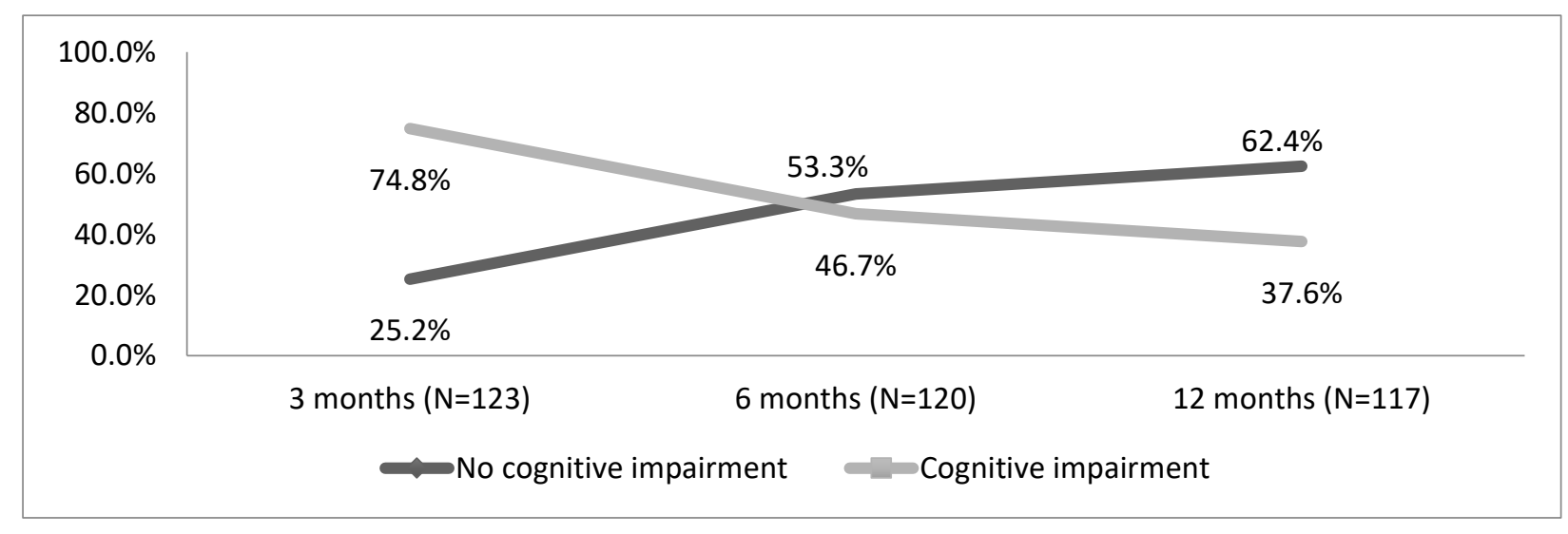

Figure 7. The incidence of cognitive sequelae occurring after 3, 6 and 12 month post stroke. 


\section{Factors associated with cognitive impairment post stroke}

\section{Univariate analysis}

Univariate analysis was made to compare the subjects with PSCI and the unscathed subjects, at 3,6 and 12 month (Tables 3 to 7, Additional file 2).

Their mean MMSE scores were $13.08( \pm 6.52)$ and $25.84( \pm 1.49)$ respectively $(p<0.001)$ at 3 month. They became $13.80( \pm 6.92)$ and $26.69( \pm 1.59)$ at 6 month versus $14.77( \pm 6.72)$ and $28.37( \pm 1.93)$ at 12 month, respectively $(p$ $<0.001)$.

The factors that were significantly associated with the cognitive function decline in the 3 time series post stroke (3, 6 and 12 month) were the elderly $(0.020<p<0.030)$, the high level of education $(p<0.049)$, the employed subjects post stroke $(p<0.044)$, the sedentary behavior $\geq 12$ hours $(p<0.001)$, the aphasia at the time of stroke occurrence $(p<0.005)$, the length of hospital stay $(p<0.029)$, the severity of the stroke $(p<0.004)$ and the degree of disability post stroke $(p<0.001)$. In addition to the above, we also found some associated stroke disabilities as follows: the anxiety $(p<0.019)$, the depression $(p<0.001)$, the pneumonia at 3 month post stroke $(<0.001<p$ $<0.024)$, the physical disorders as fatigue, pain, joint contractures, falls at 3 month post stroke and pressure ulcers $(p<0.024)$.

On the other hand, the relation with other determinants varied across these 3 time points.

At 3 month, a significant association was found between the presence of a caregiver with the cognitive impairment $(p=0.002)$. Moreover, we obtained this correlation with the duration lasting between the appearance of the stroke symptoms and the arrival to the hospital $(p=0.010)$, and the shoulder pain post stroke $(p=0.048)$.

At 6 month, the smoking status $(p=0.024)$, the university hospital $(p=0.044)$, the physical dysfunction assessed by the quality of life score at 3 month post stroke $(p=0.006)$, the epileptic seizures $(p=0.002)$, the neuropathic pain $(p=0.019)$, the shoulder pain at 3 and 6 month $(p=0.021, p=0.011$ respectively), the shoulder subluxation $(p=0.012)$, the pneumonia occurred at 6 month $(p=0.003)$ and the cognitive sequelae occurred at 3 month post stroke $(p<0.001)$ have all affected the cognitive function of the recruited subjects.

At 12 month, the higher level of household crowding index (HCI) ( $p=0.039)$, the diabetes mellitus history $(p=0.004)$, the stroke location $(p=0.006)$, the physical dysfunction assessed by the quality of life score at 3 month post stroke $(p=0.033)$, the recurrent stroke at 12 month $(p=0.006)$, the headaches at 12 month post stroke $(p=0.015)$ and the cognitive impairment occurred at 3 and 6 month post stroke $(p<0.001)$ showed a significant association with the cognitive decline.

There was no statistical significant differences with gender, Body Mass Index (BMI), eating habits, pre-existing atrial fibrillation (AF), myocardial infarction (MI), High blood pressure (HBP), family medical history, social support and types of stroke.

Multivariable analysis

Multivariable analyses using a stepwise backward logistic regression model were performed to identify the factors that were independently associated with cognitive impairment at 3,6 and 12 month after stroke (Table 8).

At 3 month post stroke, the sedentary lifestyle was positively associated with the cognitive decline $(A O R=2.797$, $95 \% \mathrm{CI}=[1.215-6.411], p=0.016)$. In contrast, the employment status post stroke and the duration between the symptoms' appearance and the arrival to hospital were negatively associated with the cognitive decline $(\mathrm{AOR}=0.295,95 \% \mathrm{CI}=[0.144-0.604], p=0.001 ; \mathrm{AOR}=0.442,95 \% \mathrm{CI}=[0.209-0.935], p=0.033$, respectively $)$. 
At 6 month, the older age $(\mathrm{AOR}=1.660,95 \% \mathrm{CI}=[1.063-2.594], p=0.026)$, the past smoking $(\mathrm{AOR}=3.949$, 95\% CI $=[1.216-12.830], p=0.022)$, the depression 3 month post stroke $(\mathrm{AOR}=4.340,95 \% \mathrm{CI}=[2.070-9.099], p$ $<0.001)$ and the pressure ulcers 3 month post stroke ( $\mathrm{AOR}=3.130,95 \% \mathrm{CI}=[1.057-9.270], p=0.039)$ affected positively the cognitive impairment; whereas, the subject education level affected negatively the cognitive impairment $(\mathrm{AOR}=0.287,95 \% \mathrm{CI}=[0.102-0.809], p=0.018)$.

At 12 month of the follow up, the results showed that the older age $(\mathrm{AOR}=1.991,95 \% \mathrm{CI}=[1.191-3.330]$, $p=0.009)$, the sedentary lifestyle $(\mathrm{AOR}=3.130,95 \% \mathrm{CI}=[1.434-6.835], p=0.004)$, the depression 12 month post stroke $(\mathrm{AOR}=2.965,95 \% \mathrm{CI}=[1.574-5.585], p=0.001)$ induced the cognitive sequelae; while, the pre-existing diabetes mellitus played a protective role for the cognitive function (AOR=0.304, 95\%CI=[0.099 - 0.940], $p=0.039)$.

Table 8. Multivariable Analysis.

\begin{tabular}{|c|c|c|}
\hline & AOR $[95 \% \mathrm{CI}]$ & p-value \\
\hline \multicolumn{3}{|l|}{ Factors associated to PSCI at 3 month $^{\mathrm{a}}$} \\
\hline Employment status post stroke & $0.295[0.144-0.604]$ & 0.001 \\
\hline Sedentary behavior & $2.797[1.215-6.411]$ & 0.016 \\
\hline Duration between the stroke symptoms onset and the hospital admission & $0.442[0.209-0.935]$ & 0.033 \\
\hline \multicolumn{3}{|l|}{ Factors associated to PSCI at 6 month $^{b}$} \\
\hline Age & $1.660[1.063-2.594]$ & 0.026 \\
\hline Education level & $0 . .287[0.102-0.809]$ & 0.018 \\
\hline Past-smoker & $3.949[1.216-12.830]$ & 0.022 \\
\hline Depression at 3 month post stroke & $4.340[2.070-9.099]$ & $<0.001$ \\
\hline Pressure ulcers at 3 month post stroke & $3.130[1.057-9.270]$ & 0.039 \\
\hline \multicolumn{3}{|l|}{ Factors associated to PSCI at 12 month $^{\mathrm{c}}$} \\
\hline Age & $1.991[1.191-3.330]$ & 0.009 \\
\hline History of diabetes mellitus & $0.304[0.099-0.940]$ & 0.039 \\
\hline Sedentary behavior & $3.130[1.434-6.835]$ & 0.004 \\
\hline Depression at 12 month post stroke & $2.965[1.574-5.585]$ & 0.001 \\
\hline
\end{tabular}

AOR: Adjusted Odds Ratio; CI: Confidence Interval.

All of these multivariate analyzes included all variables and confounding factors that had a value of $p \leq 0.05$ in the univariate analysis. The method of selection of the variables which has been chosen here is the backward stepwise method. The reference category is the absence of the factor studied.

${ }^{a}$ Classification table: Global percentage 83.5\%, Model fit test <0.001, Nagelkerke R-Square 0.527, HosmerLemeshow test 0.579

b Classification table: Global percentage $82.2 \%$, Model fit test $<0.001$, Nagelkerke R-Square 0.527 , HosmerLemeshow test 0.990

${ }^{\mathrm{c}}$ Classification table: Global percentage 84.3\%, Model fit test <0.001, Nagelkerke R-Square 0.563, HosmerLemeshow test 0.912

\section{Discussion}

To the best of our knowledge, it is the first study of its kind in Lebanon. The main objective was to determine the incidence and the predictors of the cognitive impairment at three time points post first-ever stroke: 3,6 and 12 month.

\section{Incidence of PSCI}

Our findings showed that a significant proportion of stroke survivors had cognitive deficits, especially in the short term, after 3 months after stroke. The cognition improved gradually at 6 and 12 month by decreasing the incidence 
of its impairment. These results agreed with previous studies, as of the study of Li et al., 2020[39], Nys et al., 2007[40].

\section{Predictors of the PSCI}

Effect of socio-demographic characteristics and lifestyle

Age and education level were related to the risk of PSCI. There is evidence that older survivors compared to younger survivors, had significantly faster decline of the global cognition. This latter would decrease exponentially as age increases[41, 42].

Unlike to age, the high education level was associated with better cognitive performances[41], [42]. As well as the survivors who returned to work after stroke presented with less cognitive impairment than those who did not return to work, this is consistent with the study of kemp et al. 2019[43] and other similar previous papers that considered the employment as a major determinant of functional recovery and enhancing the cognitive domain[44, 45].

A study conducted in Malaysia by Othman et al., 2016[46] addressing the caregiver burden and the risk of PSCI, can elucidate its high incidence between the participants cared for by caregivers. The caregivers are generally misunderstood and ill-prepared for their tasks and responsibilities they must face at home[47].

At long term, 12 month post stroke, the cognitive impairment incidence was significantly higher among the crowded households ( $>1$ person/room) that indicate the low socio-economic level. This result was similar to the one reported by Mohd Zulkifly et al., 2016[48].

In contrast, the association between the gender and the cognitive impairment, found in multiple papers [11, 40, 41] was not resulted by our findings, which can be explained by the small sample size recruited.

Regarding the lifestyle, as per Morsund et al. (2018)[49], heavy and former smokers showed a faster cognitive decline than non-smokers. This study supports our findings at 6 month post stroke.

Moreover, The odds of cognitive impairment increased 3 times as the sitting hours increased to $\geq 12$ hours/day, which was highlighted also by a study done among 5 population cohorts from Greece, Australia, USA, Japan and Singapore in 2020[50].

Whereas, no association was obtained with the dietary intake, the BMI and the social support while some previous literature showed a significant relation between these variables and the PSCI[48, 51-53]. This difference can be explained also by the small sample size enrolled in our study.

\section{Effect of pre-existing conditions}

Our findings did not notice any statistical relation between the AF, MI, HBP and family medical history with the cognitive impairment. However, many international studies deduced this relation and mentioned the risk induced by these factors $[12,54,55]$. Also, these studies defined the diabetes mellitus as a risk factor for cognitive function decrease, which it contradicts with our finding where the history of diabetes mellitus had a remarkable protective effect on the cognitive function. It could be explained by the misclassification of the elderly due to a lack of diagnosis of diabetes mellitus.

Effect of stroke characteristics and its severity

Similarly to our findings, the subjects with aphasia at the time of stroke occurrence had high incidence of cognitive deficit at the 3 time points post stroke than those without aphasia[51, 54]. 
The length of hospital stay $>8$ days at the stroke occurrence was associated with low scores of MMSE i.e. high incidence of short and long term PSCI. The study of Mathews et al., 2013[56] underlined this relation between hospitalization period and the cognitive decline.

In the Korean study of Lim et al., 2018[57], the duration from stroke symptoms onset to admission period was found a significant predictor of PSCI, whereas, our study revealed that it had a protective effect at 3 month post stroke.

The severity of stroke and the degree of disability were not assessed at baseline unfortunately because of lack of assessment tools in most of the recruited hospitals and the delay of their approval was an obstacle. So, we could not do the comparison between the baseline scores and the three-time series scores. Otherwise, the high NIHSS and mRS scores at 3, 6 and 12 month were positively associated with low MMSE scores. Zulkifly et al., 2016 stated that "stroke survivors with cognitive impairment are most likely to be dependent in ADL and having high stroke severity"[48].

There was no significant difference found between ischemic and hemorrhagic strokes in our study.

\section{Effect of disabilities post stroke}

Our findings underlined the strong association between the psychiatric disorders, anxiety and depression at 3, 6 and 12 month post stroke with the cognitive decline. To note that the depression at early stage (3 month post stroke) increased 4 times the risk of cognitive deficit at 6 month and the depression at 12 month increased 2 times this risk at 12 month post stroke. These results were comparable to many studies' results[58, 59]. Therefore, the focus on anxiety and depression in post-stroke patients is paramount in order to specifically guide rehabilitation strategies in the different stages of stroke.

Subjects with motor deficit after stroke, the falls, the general pain, the central pain at 3 and 12 month, the fatigue, the joint contractures, the muscle spasticity at 6 and 12 month and the pressure ulcers experienced lower quality of life, greater cognitive and functional decline, similarly to numerous international studies[47, 54, 58, 60, 61]. The control of motor movement in executing ADL is a main problem after stroke[48].

Concerning the epileptic seizures, a review article by $\mathrm{Xu}$ in 2018 declared that studies have indicated two peaks in post stroke seizures occurrence, the first day and 6-12 month after a stroke[62]. And Van Tuijl et al., 2020 deduced that the cognitive function was impaired in post stroke epilepsy patients[63]. This was in concordance with our findings.

\section{Strengths and Limitations}

This study has some limitations. The main limitation was the small sample size recruited following the unique study considering a low prevalence of stroke in Lebanon[23] of 3.9\% according to other countries. The second limitation that hospitals were limited to the regions of Beirut and Mount Lebanon, regardless of the subjects came from all governorates. Hence, they affected the generalizability of our results. Future studies should take into account all the weak points and a larger sample size from all Lebanon regions must be included to confirm our findings.

However the results were statistically significant, there was a high loss to follow-up due to the large number of deaths at 3 month, the fact that we could not assess their cognitive function therefore we think that the cognitive function is underestimated in our study. Conclusions should be confirmed in a larger cohort. Thus, our findings may be beneficial to draw hypotheses on stroke burden and its complications, especially the cognitive impairment, in the country for future analyses. 
The strengths of the study were that it was a multicenter longitudinal prospective study and one of the few such studies done in Lebanon, the use of standardized validated reliable objective and international measuring instruments, and were performed by very qualified and well trained investigators face to face with the subjects.

\section{Conclusion}

PSCI is a major cause of handicap; it affects memory, thinking, orientation, comprehension, calculation, learning capacity, language, and judgment. We found that it had a very high incidence in Lebanon especially at early stage, at 3 month post stroke. The predictors resulted in our study were all similar to those obtained by previous international studies. They were the older age, the past smoking, the presence of a caregiver, the crowded households, the sedentary lifestyle, the aphasia at the time of stroke occurrence, the length of hospital stay, the severity of stroke, the severe disability, the anxiety and depression post stroke, the physical complications post stroke, and the epileptic seizures. Identifying these risk factors would be useful in the management of stroke survivors as well as the prevention of further cognitive decline. In addition, it improves psychological wellbeing through an effective intervention.

Finally, there is a need to increase public awareness. A valuable coordination and collaboration between healthcare professionals and a solid support from the families and caregivers contributes to the recovery of stroke survivors. Thus, an emergency rehabilitation program for patients and their families is essential to enable them to achieve their highest possible level of independence.

\section{Abbreviations}

PSCI: Post-stroke cognitive impairment; ADL: Activities of daily living; WHO: World Health Organization; MMSE: Mini-Mental State Examination; NIHSS: National Institutes of Health Stroke Scale; mRS: Modified Rankin Scale; QVSFS: Questionnaire for Verifying Stroke-Free Status; SF12: Short Form Health Survey 12; PCS: Physical Component Summary; MCS: Mental Component Summary; HADS: Hospital Anxiety and Depression Scale; FSS: Fatigue Severity Scale; USA: United States of America; SD: Standard Deviation; ANOVA: Analysis Of Variance; NS: Not significant; AOR: Adjusted Odds Ratio; CI: Confidence Interval; HCI: Household Crowding Index; BMI: Body Mass Index; AF: Atrial Fibrillation; MI: Myocardial Infarction, HBP: High Blood Pressure.

\section{Supplementary Materials}

Additional Files 1 and 2 include the descriptive and univariate analysis.

Additional File 3 include the appendix: additional used definitions and scales.

\section{Acknowledgements}

We would like to acknowledge the participating hospitals. We thank the patients and caregivers whose contribution made this study possible. In addition, Dr. Sylvia Saade and her student Ms. Mariam Chaalan, who initiate the data collection with us but they could not continue the process.

\section{Additional Information}

The authors declared that they have no known competing financial or non-financial interests or personal relationships that could have appeared to influence the work reported in this paper. 


\section{Funding}

This work was supported by the "Association Médicale Franco-Libanaise (AMFL)" and "Institut National de Santé Public, Epidémiologie Clinique et Toxicologie- Liban (INSPECT-LB)". The funders had no involvement in the conduct of this article.

\section{Data availability statement}

Data available upon request due to privacy and ethical restrictions.

\section{References}

[1] V. Klamroth-Marganska, "Stroke Rehabilitation: Therapy Robots and Assistive Devices," Adv. Exp. Med. Biol., vol. 1065, pp. 579-587, 2018, doi: 10.1007/978-3-319-77932-4_35.

[2] S. Broussy et al., "Post-stroke pathway analysis and link with one year sequelae in a French cohort of stroke patients: the PAPASePA protocol study," BMC Health Serv. Res., vol. 19, Oct. 2019, doi: 10.1186/s12913019-4522-2.

[3] D. Rohde et al., "Cognitive impairment and medication adherence post-stroke: A five-year follow-up of the ASPIRE-S cohort," PLoS ONE, vol. 14, no. 10, Oct. 2019, doi: 10.1371/journal.pone.0223997.

[4] N. K. Al-Qazzaz, S. H. Ali, S. A. Ahmad, S. Islam, and K. Mohamad, "Cognitive impairment and memory dysfunction after a stroke diagnosis: a post-stroke memory assessment," Neuropsychiatr. Dis. Treat., vol. 10, pp. 1677-1691, Sep. 2014, doi: 10.2147/NDT.S67184.

[5] H. Chertkow et al., "Diagnosis and treatment of dementia: 3. Mild cognitive impairment and cognitive impairment without dementia," CMAJ Can. Med. Assoc. J., vol. 178, no. 10, pp. 1273-1285, May 2008, doi: 10.1503/cmaj.070797.

[6] A. Busse, M. C. Angermeyer, and S. G. Riedel-Heller, "Progression of mild cognitive impairment to dementia: a challenge to current thinking," Br. J. Psychiatry J. Ment. Sci., vol. 189, pp. 399-404, Nov. 2006, doi: 10.1192/bjp.bp.105.014779.

[7] Y. Qu et al., "Prevalence of Post-Stroke Cognitive Impairment in China: A Community-Based, CrossSectional Study,” PLoS ONE, vol. 10, no. 4, Apr. 2015, doi: 10.1371/journal.pone.0122864.

[8] H. Ihle-Hansen et al., "Incidence and subtypes of MCI and dementia 1 year after first-ever stroke in patients without pre-existing cognitive impairment," Dement. Geriatr. Cogn. Disord., vol. 32, no. 6, pp. 401-407, 2011, doi: 10.1159/000335361.

[9] P. B. Gorelick et al., "Vascular Contributions to Cognitive Impairment and Dementia," Stroke J. Cereb. Circ., vol. 42, no. 9, pp. 2672-2713, Sep. 2011, doi: 10.1161/STR.0b013e3182299496.

[10] C. Ballard, E. Rowan, S. Stephens, R. Kalaria, and R. A. Kenny, "Prospective follow-up study between 3 and 15 months after stroke: improvements and decline in cognitive function among dementia-free stroke survivors $>75$ years of age," Stroke, vol. 34, no. 10, pp. 2440-2444, Oct. 2003, doi: 10.1161/01.STR.0000089923.29724.CE.

[11] J. W. Lo et al., "Profile of and risk factors for poststroke cognitive impairment in diverse ethnoregional groups," Neurology, vol. 93, no. 24, pp. e2257-e2271, 10 2019, doi: 10.1212/WNL.0000000000008612.

[12] R. N. Kalaria, R. Akinyemi, and M. Ihara, "Stroke injury, cognitive impairment and vascular dementia," Biochim. Biophys. Acta, vol. 1862, no. 5, pp. 915-925, May 2016, doi: 10.1016/j.bbadis.2016.01.015. 
[13] G. Hagberg et al., "Predictors for Favorable Cognitive Outcome Post-Stroke: A-Seven-Year Follow-Up Study," Dement. Geriatr. Cogn. Disord., vol. 48, no. 1-2, pp. 45-55, 2019, doi: 10.1159/000501850.

[14] M. D. Mijajlović et al., "Post-stroke dementia - a comprehensive review," BMC Med., vol. 15, no. 1, p. 11, Jan. 2017, doi: 10.1186/s12916-017-0779-7.

[15] M. El-Hajj, P. Salameh, S. Rachidi, and H. Hosseini, “The epidemiology of stroke in the Middle East," Eur. Stroke J., vol. 1, no. 3, pp. 180-198, Sep. 2016, doi: 10.1177/2396987316654338.

[16] N. Lahoud et al., "Care and Discharge Outcome of Acute Stroke in Lebanon: A Hospital-Based Study," J. Nerv. Ment. Dis., vol. 206, no. 8, pp. 637-643, Aug. 2018, doi: 10.1097/NMD.0000000000000856.

[17] H. A. Salhab, P. Salameh, H. Hajj, and H. Hosseini, "Stroke in the Arab World: A bibliometric analysis of research activity (2002-2016)," eNeurologicalSci, vol. 13, pp. 40-45, Dec. 2018, doi: 10.1016/j.ensci.2018.11.010.

[18] P. Salameh et al., "Self-reported history of stroke and long-term living conditions near air pollution sources: results of a national epidemiological study in Lebanon," Environ. Monit. Assess., vol. 190, no. 3, p. 153, Feb. 2018, doi: 10.1007/s10661-018-6545-2.

[19] M. El-Hajj, P. Salameh, S. Rachidi, A. Al-Hajje, and H. Hosseini, "Development of a risk of stroke score in the Lebanese population," Clin. Epidemiol. Glob. Health, vol. 7, no. 1, pp. 88-97, Mar. 2019, doi: 10.1016/j.cegh.2018.02.003.

[20] E. von Elm et al., "The Strengthening the Reporting of Observational Studies in Epidemiology (STROBE) Statement: guidelines for reporting observational studies," Int. J. Surg. Lond. Engl., vol. 12, no. 12, pp. 1495-1499, Dec. 2014, doi: 10.1016/j.ijsu.2014.07.013.

[21] "World Medical Association Declaration of Helsinki: Ethical Principles for Medical Research Involving Human Subjects,” JAMA, vol. 310, no. 20, p. 2191, Nov. 2013, doi: 10.1001/jama.2013.281053.

[22] “ICD-10 Version:2016.” http://apps.who.int/classifications/icd10/browse/2016/en\#/G46 (accessed Sep. 22, 2017).

[23] A. R. Jurjus, R. A. Tohme, G. Ephrem, I. A. H. Hussein, and R. Jurjus, "Incidence and prevalence of circulatory diseases in Lebanon: a physician's inquiry," Ethn. Dis., vol. 19, no. 1, p. 1, 2009.

[24] “Stroke guidelines," RCP London, Oct. 03, 2016. https://www.rcplondon.ac.uk/guidelines-policy/strokeguidelines (accessed Sep. 12, 2017).

[25] K. B. Lee et al., "Six-month functional recovery of stroke patients: a multi-time-point study," Int. J. Rehabil. Res. Int. Z. Rehabil. Rev. Int. Rech. Readaptation, vol. 38, no. 2, pp. 173-180, Jun. 2015, doi: 10.1097/MRR.0000000000000108.

[26] S. T. Creavin et al., "Mini-Mental State Examination (MMSE) for the detection of dementia in clinically unevaluated people aged 65 and over in community and primary care populations," Cochrane Database Syst. Rev., no. 1, p. CD011145, Jan. 2016, doi: 10.1002/14651858.CD011145.pub2.

[27] F. B. Young, C. J. Weir, and K. R. Lees, "Comparison of the National Institutes of Health Stroke Scale With Disability Outcome Measures in Acute Stroke Trials,” Stroke, vol. 36, no. 10, pp. 2187-2192, Oct. 2005, doi: 10.1161/01.STR.0000181089.41324.70.

[28] J. K. Harrison, K. S. McArthur, and T. J. Quinn, "Assessment scales in stroke: clinimetric and clinical considerations," Clin. Interv. Aging, vol. 8, pp. 201-211, 2013, doi: 10.2147/CIA.S32405. 
[29] G. G. FAOTA EdD, OTR, Stroke Rehabilitation: A Function-Based Approach. Elsevier Health Sciences, 2015.

[30] B. Cheng et al., "Influence of stroke infarct location on functional outcome measured by the modified rankin scale," Stroke, vol. 45, no. 6, pp. 1695-1702, Jun. 2014, doi: 10.1161/STROKEAHA.114.005152.

[31] "Modified Rankin Scale: Modified Rankin Scale," May 2017, Accessed: Sep. 23, 2017. [Online]. Available: http://emedicine.medscape.com/article/2172455-overview.

[32] D. Cioncoloni et al., "Relationship between the modified Rankin Scale and the Barthel Index in the process of functional recovery after stroke," NeuroRehabilitation, vol. 30, no. 4, pp. 315-322, 2012, doi: 10.3233/NRE-2012-0761.

[33] A. L. Fitzpatrick et al., "Symptoms and risk factors for stroke in a community-based observational sample in Viet Nam," J. Epidemiol. Glob. Health, vol. 2, no. 3, pp. 155-163, Sep. 2012, doi: 10.1016/j.jegh.2012.06.001.

[34] I. Sabbah, N. Drouby, S. Sabbah, N. Retel-Rude, and M. Mercier, "Quality of Life in rural and urban populations in Lebanon using SF-36 Health Survey," Health Qual. Life Outcomes, vol. 1, no. 1, p. 30, Aug. 2003, doi: 10.1186/1477-7525-1-30.

[35] C. Vansimaeys et al., "Combining Standard Conventional Measures and Ecological Momentary Assessment of Depression, Anxiety and Coping Using Smartphone Application in Minor Stroke Population: A Longitudinal Study Protocol,” Front. Psychol., vol. 8, p. 1172, 2017, doi: 10.3389/fpsyg.2017.01172.

[36] M. Curtin, M. Egan, and J. Adams (PhD), Occupational Therapy for People Experiencing Illness, Injury Or Impairment E-Book(previously Entitled Occupational Therapy and Physical Dysfunction): Promoting Occupation and Participation. Elsevier Health Sciences, 2016.

[37] P. O. Valko, C. L. Bassetti, K. E. Bloch, U. Held, and C. R. Baumann, "Validation of the Fatigue Severity Scale in a Swiss Cohort," Sleep, vol. 31, no. 11, pp. 1601-1607, Nov. 2008.

[38] E. Rosti-Otajärvi, P. Hämäläinen, A. Wiksten, T. Hakkarainen, and J. Ruutiainen, "Validity and reliability of the Fatigue Severity Scale in Finnish multiple sclerosis patients,” Brain Behav., vol. 7, no. 7, Jun. 2017, doi: 10.1002/brb3.743.

[39] J. Li et al., "Association Between Early Cognitive Impairment and Midterm Functional Outcomes Among Chinese Acute Ischemic Stroke Patients: A Longitudinal Study,” Front. Neurol., vol. 11, Feb. 2020, doi: 10.3389/fneur.2020.00020.

[40] G. M. S. Nys, M. J. E. van Zandvoort, P. L. M. de Kort, B. P. W. Jansen, E. H. F. de Haan, and L. J. Kappelle, "Cognitive disorders in acute stroke: prevalence and clinical determinants," Cerebrovasc. Dis. Basel Switz., vol. 23, no. 5-6, pp. 408-416, 2007, doi: 10.1159/000101464.

[41] D. A. Levine et al., "Risk Factors for Poststroke Cognitive Decline," Stroke, Apr. 2018, doi: 10.1161/STROKEAHA.117.018529.

[42] J.-H. Sun, L. Tan, and J.-T. Yu, "Post-stroke cognitive impairment: epidemiology, mechanisms and management," Ann. Transl. Med., vol. 2, no. 8, Aug. 2014, doi: 10.3978/j.issn.2305-5839.2014.08.05.

[43] J. van der Kemp, W. J. Kruithof, T. C. W. Nijboer, C. A. M. van Bennekom, C. van Heugten, and J. M. A. Visser-Meily, "Return to work after mild-to-moderate stroke: work satisfaction and predictive factors," Neuropsychol. Rehabil., vol. 29, no. 4, pp. 638-653, Apr. 2019, doi: 10.1080/09602011.2017.1313746. 
[44] S. Mahon et al., "Determinants, Prevalence, and Trajectory of Long-Term Post-Stroke Cognitive Impairment: Results from a 4-Year Follow-Up of the ARCOS-IV Study," Neuroepidemiology, vol. 49, no. 3-4, pp. 129-134, 2017, doi: 10.1159/000484606.

[45] S. M. Hatem et al., "Rehabilitation of Motor Function after Stroke: A Multiple Systematic Review Focused on Techniques to Stimulate Upper Extremity Recovery," Front. Hum. Neurosci., vol. 10, Sep. 2016, doi: 10.3389/fnhum.2016.00442.

[46] Z. Othman, W. ST, I. Drahman, and R. Zakaria, "Caregiver Burden is Associated with Cognitive Decline and Physical Disability of Elderly Post-Stroke Patients." Jul. 28, 2016, doi: 10.6084/m9.figshare.3503801.v1.

[47] S. K. Lui and M. H. Nguyen, "Elderly Stroke Rehabilitation: Overcoming the Complications and Its Associated Challenges," Current Gerontology and Geriatrics Research, Jun. 27, 2018. https://www.hindawi.com/journals/cggr/2018/9853837/ (accessed Jun. 09, 2020).

[48] M. F. Mohd Zulkifly, S. E. Ghazali, N. Che Din, D. K. A. Singh, and P. Subramaniam, “A Review of Risk Factors for Cognitive Impairment in Stroke Survivors," The Scientific World Journal, May 31, 2016. https://www.hindawi.com/journals/tswj/2016/3456943/ (accessed Jun. 07, 2020).

[49] ̊. H. Morsund et al., "The development of cognitive and emotional impairment after a minor stroke: A longitudinal study," Acta Neurol. Scand., vol. 140, no. 4, pp. 281-289, Oct. 2019, doi: 10.1111/ane.13143.

[50] C. M. Maasakkers et al., "The Association of Sedentary Behaviour and Cognitive Function in People Without Dementia: A Coordinated Analysis Across Five Cohort Studies from COSMIC," Sports Med., vol. 50, no. 2, pp. 403-413, Feb. 2020, doi: 10.1007/s40279-019-01186-7.

[51] Tang Eugene YH et al., "Longitudinal Effect of Stroke on Cognition: A Systematic Review," J. Am. Heart Assoc., vol. 7, no. 2, p. e006443, 15 2018, doi: 10.1161/JAHA.117.006443.

[52] D. Lo Coco, G. Lopez, and S. Corrao, "Cognitive impairment and stroke in elderly patients," Vasc. Health Risk Manag., vol. 12, pp. 105-116, Mar. 2016, doi: 10.2147/VHRM.S75306.

[53] T. Elloker and A. J. Rhoda, "The relationship between social support and participation in stroke: A systematic review," Afr. J. Disabil., vol. 7, Oct. 2018, doi: 10.4102/ajod.v7i0.357.

[54] P. N. Renjen, C. Gauba, and D. Chaudhari, “Cognitive Impairment After Stroke,” Cureus, vol. 7, no. 9, Sep. 2015, doi: 10.7759/cureus.335.

[55] W. Srithumsuk et al., "The importance of stroke as a risk factor of cognitive decline in community dwelling older and oldest peoples: the SONIC study," BMC Geriatr., vol. 20, Jan. 2020, doi: 10.1186/s12877-0201423-5.

[56] S. B. Mathews, S. E. Arnold, and C. N. Epperson, "Hospitalization and Cognitive Decline: Can the Nature of the Relationship Be Deciphered?," Am. J. Geriatr. Psychiatry Off. J. Am. Assoc. Geriatr. Psychiatry, vol. 22, no. 5, pp. 465-480, May 2014, doi: 10.1016/j.jagp.2012.08.012.

[57] H.-S. Lim, S. M. Kim, and D.-W. Kang, "Quantitative Predictive Models for the Degree of Disability After Acute Ischemic Stroke," J. Clin. Pharmacol., vol. 58, no. 4, pp. 549-557, Apr. 2018, doi: 10.1002/jcph.1039.

[58] O. Segev-Jacubovski, T. Herman, G. Yogev-Seligmann, A. Mirelman, N. Giladi, and J. M. Hausdorff, "The interplay between gait, falls and cognition: can cognitive therapy reduce fall risk?," Expert Rev. Neurother., vol. 11, no. 7, pp. 1057-1075, Jul. 2011, doi: 10.1586/ern.11.69. 
[59] MC Quattropani, Geraci A, and Lenzo V, “(7) (PDF) Post-stroke anxiety and depression: Relationships to cognitive rehabilitation outcome,” $\quad$ ResearchGate, 2018. https://www.researchgate.net/publication/323723788_Post-

stroke_anxiety_and_depression_Relationships_to_cognitive_rehabilitation_outcome (accessed Jun. 10, 2020).

[60] R. A. Harrison and T. S. Field, "Post stroke pain: identification, assessment, and therapy," Cerebrovasc. Dis. Basel Switz., vol. 39, no. 3-4, pp. 190-201, 2015, doi: 10.1159/000375397.

[61] M. Graber et al., "Association Between Fatigue and Cognitive Impairment at 6 Months in Patients With Ischemic Stroke Treated With Acute Revascularization Therapy," Front. Neurol., vol. 10, 2019, doi: 10.3389/fneur.2019.00931.

[62] M. Y. Xu, "Poststroke seizure: optimising its management," Stroke Vasc. Neurol., vol. 4, no. 1, Mar. 2019, doi: 10.1136/svn-2018-000175.

[63] J. H. van Tuijl, E. P. M. van Raak, R. J. van Oostenbrugge, A. P. Aldenkamp, and R. P. W. Rouhl, “Cognition and quality of life in patients with poststroke epilepsy: A case-control study," Epilepsy Behav., vol. 104, p. 106444, Mar. 2020, doi: 10.1016/j.yebeh.2019.106444.

\section{Author contributions statement}

C.B. contributed to the study design, data collection, data analysis, and drafting of the manuscript. W.K., M.T., N.S. contributed to the data collection, editing of the manuscript. P.S., H.H. contributed to the study design, and editing of the manuscript. All authors have revised the manuscript and approved the submitted version.

\section{Figure Legends}

- $\quad$ Figure 1. Flow diagram of the steps followed to obtain the sample of the study.

A total of 20 hospitals were visited, of which 10 agreed to participate in the study. Out of 183 subjects meeting the required inclusion criteria, 150 were recruited in the study ( $82 \%$ of the response rate), of whom 117 subjects completed all the follow-up.

- $\quad$ Figure 7. The incidence of cognitive sequelae occurring after 3, 6 and 12 month post stroke.

At 3 month post stroke, the majority of the 123 survivors $(74.8 \%)$ were cognitively impaired (MMSE < 24) compared to $25.2 \%$ cognitively intact. The incidence of sequelae gradually decreased over the time at 6 and 12 months post stroke, with percentages of $46.7 \%$ and $37.6 \%$ respectively. 
Number of visited hopsitals in Mount Lebanon and Beirut: $\mathbf{N}=\mathbf{2 0}$

Number of hospitals participating in the study $(\mathrm{N}=10)$ :

Hôtel Dieu de France, Clinique du Levant, Al Hayat Hospital, Mount Lebanon Hospital, AL Sahel Hospital, Rafic Hariri University Hospital , Zahraa Hospital, Hôpital Sacré-Coeur, Kesserwan Medical Center and Middle East Institute of Health

Number of subjects m eeting the inclusion criteria $(N=183)$ : Hôtel Dieu de France: $\mathrm{n}=22$, Clinique du Levant. $\mathrm{n}=5$, Al Hayat Hospital: $n=15$, Mount Lebanon Hospital: $n=39$, Al Sahel Hospital: $n=17$, Rafic Hariri Univer sity Hospital: $n=22$, Zahraa Hospital: n= 48, Hôpital Sacré-Coeur: n= 5, Kesserwan Medical Center: $n=4$, Middle East Institute of Health: $n=6$
Number of subjects who refused the participation: $\mathrm{N}=19$

Number of subjects whose the communic ation w as im possible: $\mathrm{N}=14$
Number of subjects included in the analysis of the study ( $N=$ 150):

Hôtel Dieu de France: $\mathrm{n}=18$, Clinique du Levant. $\mathrm{n}=5, \mathrm{Al}$ Hayat Hospital: $\mathrm{n}=14$, Mount Lebanon Hospital: $\mathrm{n}=36, \mathrm{Al}$ Sahel Hospital: $\mathrm{n}=16$, Rafic Hariri University Hospital: $\mathrm{n}=12$, Zahraa Hospital: $\mathrm{n}=36$, Hôpital Sacré-Coeur: $\mathrm{n}=5$, Kesserwan Medical Center: $n=4$, Middle East Institute of Heal th: $n=4$

\begin{tabular}{|c|}
\hline Total number of subjects who completed the whole \\
period of follow-up (3,6 and 12 month): \\
$\mathrm{N}=117$
\end{tabular}

Number of subjects lost to followup $(\mathrm{N}=33)$ :

- 32 deceased (27 at 3 months, 3 at 6 months et 2 at 12 months)

- Loss of contact with 1 subject at 12 months.

\section{Figure 1}

Flow diagram of the steps followed to obtain the sample of the study. 


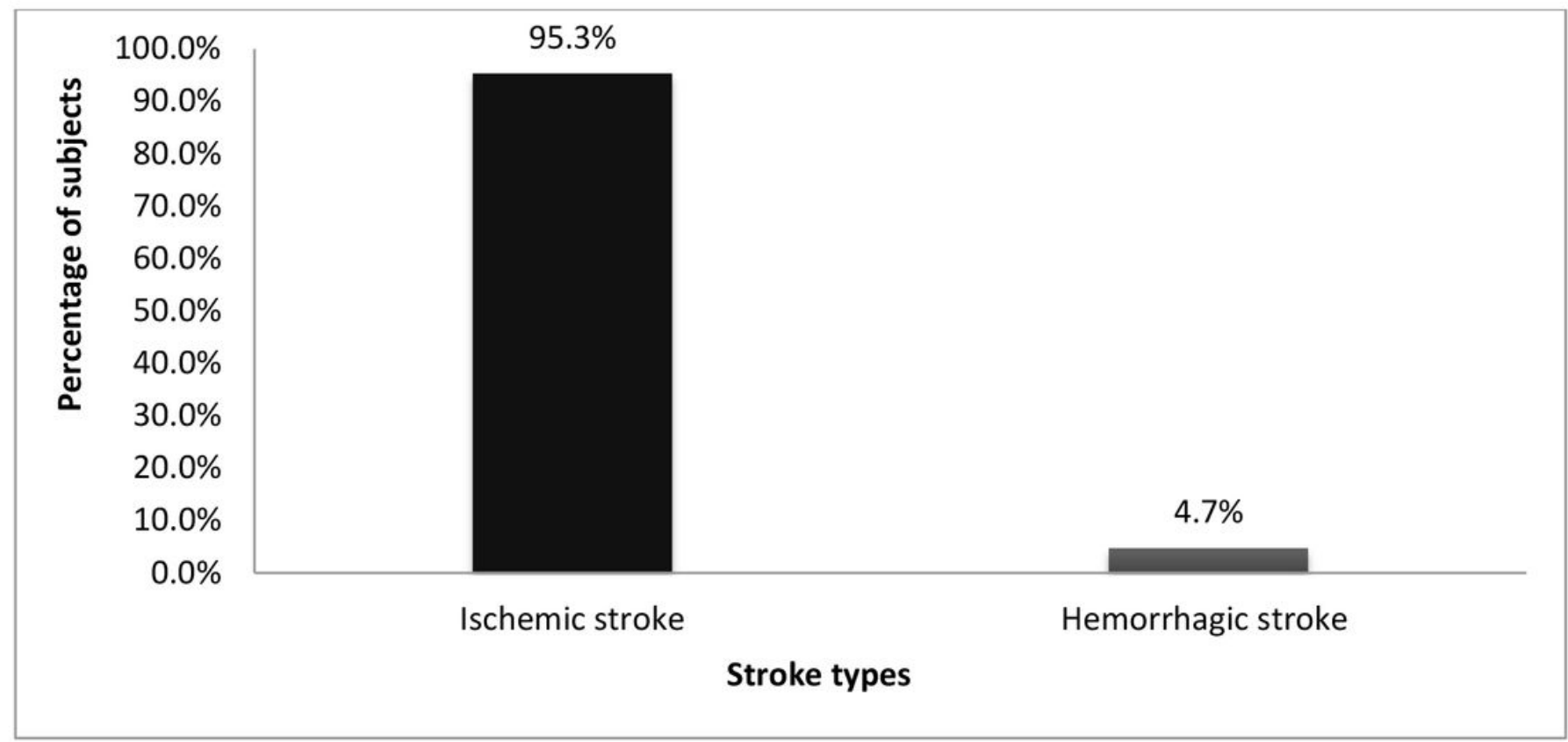

Figure 2

The percentage of stroke types.

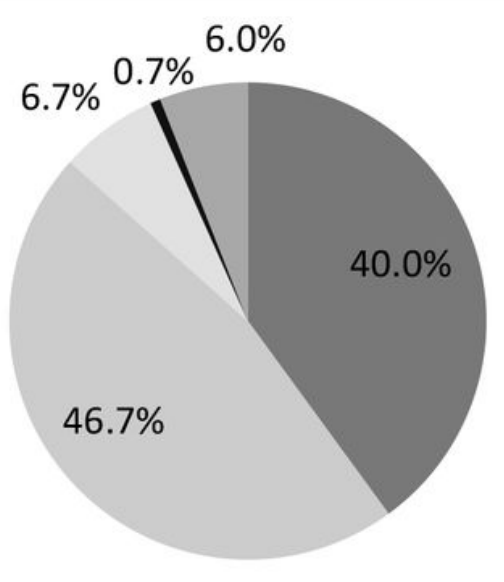

Right hemisphere

- Left hemisphere

Bilateral hemisphere

- Brainstem

- Cerebellum

Figure 3

The distribution of stroke locations. 
Sudden loss of the ability to express ideas verbally or in writing

Sudden loss of the ability to understand what
in $\quad$ people are saying

जे

Sudden painless loss of vision in one or both eyes

Sudden numbness or a dead feeling on one side of the body

Sudden painless weakness on one side of the body

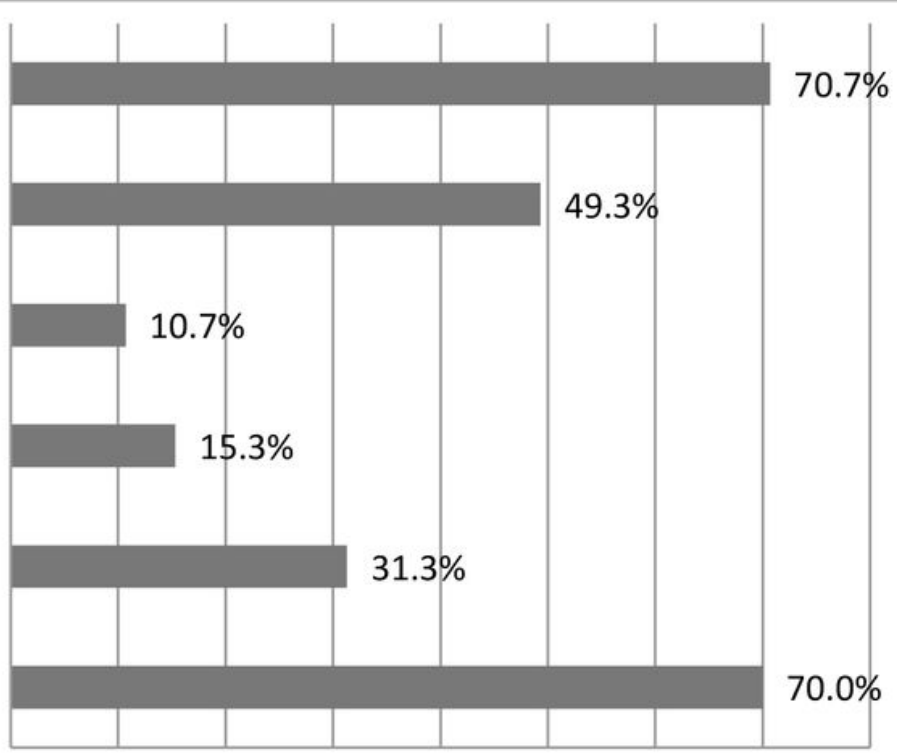

$0.0 \% \quad 10.0 \% 20.0 \% 30.0 \%$ 40.0\% 50.0\% $60.0 \%$ 70.0\% 80.0\%

Percentage

\section{Figure 4}

The percentage of symptoms experienced during the occurrence of stroke.

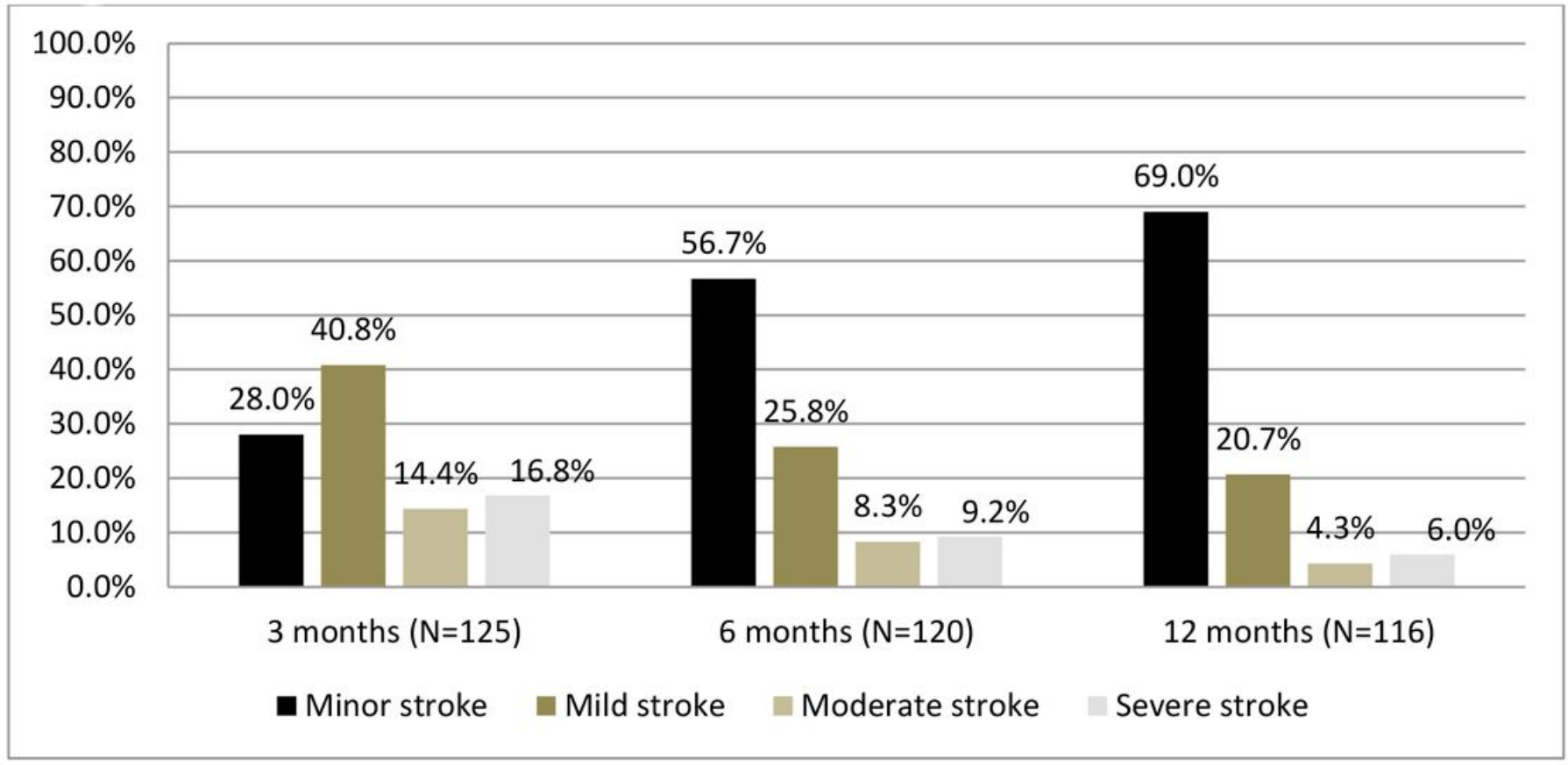

\section{Figure 5}

The severity of the stroke measured by the NIHSS scale. 


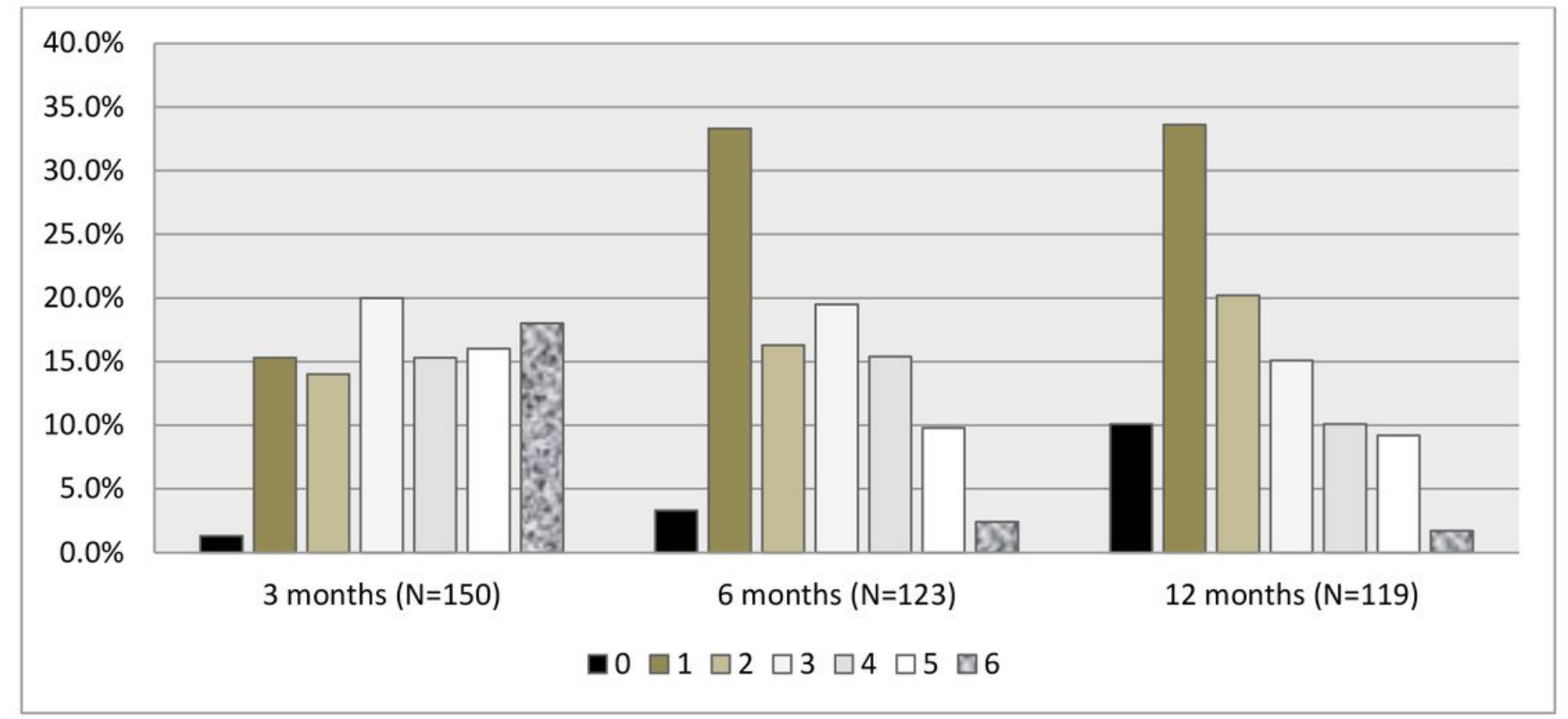

\section{Figure 6}

The degree of disability measured by the modified Rankin Scale (mRS) among Lebanese stroke survivors aged $\geq 18$ years old admitted to hospitals in Mount Lebanon and Beirut between February and May 2018. It's divided into 7 levels as follows: 0 : No symptoms; 1 : No significant disability despite symptoms; able to perform all the duties and usual activities; 2: Low incapacity; unable to accomplish many previous things, but capable of taking care of its own affairs without assistance; 3 : inability to moderate; needing help, but able to walk without assistance; 4: Moderately serious disability; unable to walk without assistance and unable to meet physical needs without assistance; 5 : Serious disability; bedridden, incontinent and demanding necessary attention and constant nursing care; 6: Death. 


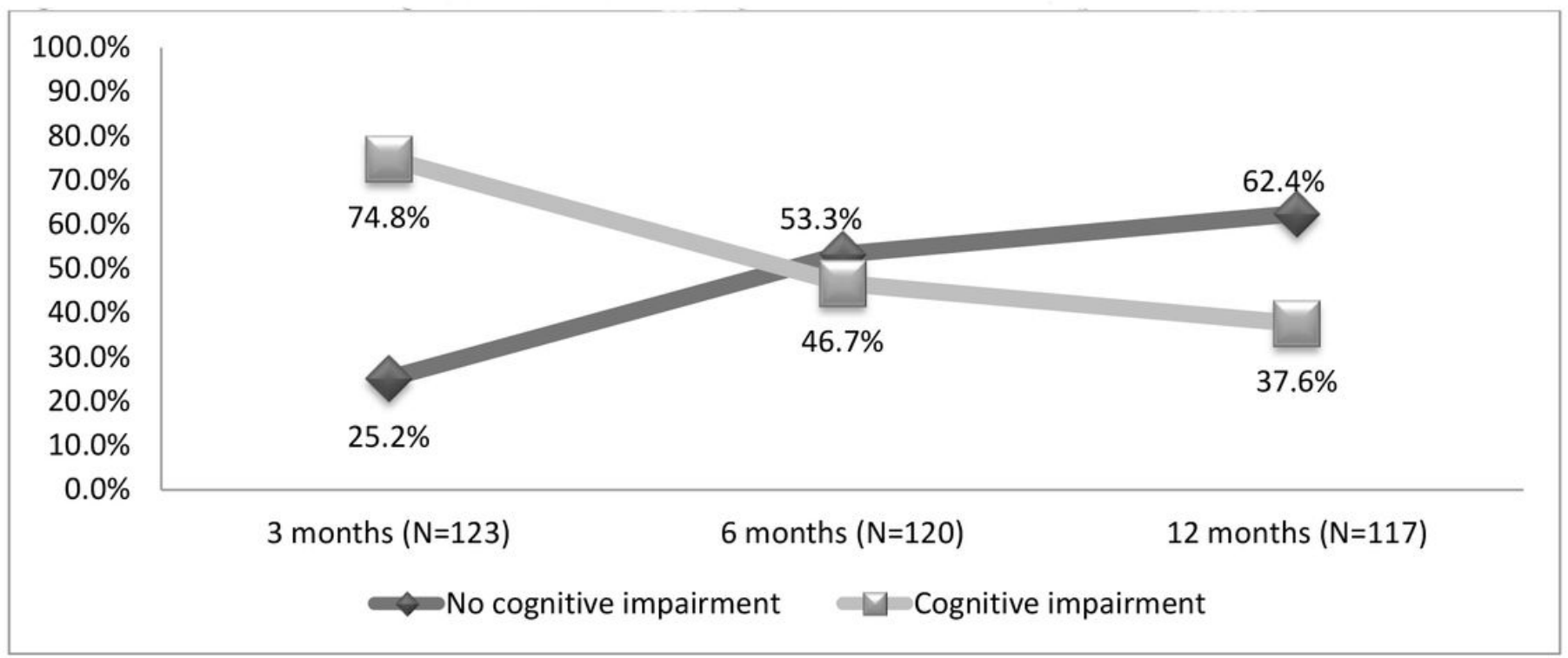

Figure 7

The incidence of cognitive sequelae occurring after 3,6 and 12 month post stroke.

\section{Supplementary Files}

This is a list of supplementary files associated with this preprint. Click to download.

- Table1.pdf

- Table2.pdf

- Table3.pdf

- Table4.pdf

- Table5.pdf

- Table6.pdf

- Table7.pdf

- Table8.pdf

- AdditionalFile1.DescriptiveAnalysis.pdf

- AdditionalFile2UnivariateAnalysis.pdf

- AdditionalFile3Appendix.pdf 